Canadian Journal of Fisheries and Aquatic Sciences

Canadian

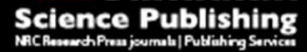

Journal canadien des sciences halieutiques et aquatiques

\title{
Juvenile steelhead movements in relation to stream habitat, population density, and body size: consequences for individual growth rates
}

\begin{tabular}{|r|l|}
\hline Journal: & Canadian Journal of Fisheries and Aquatic Sciences \\
\hline Manuscript ID & cjfas-2016-0007.R1 \\
\hline Manuscript Type: & Article \\
\hline Date Submitted by the Author: & 11 -Mar-2016 \\
\hline Complete List of Authors: & $\begin{array}{l}\text { Myrvold, Knut; University of Idaho, Fish and Wildlife Sciences } \\
\text { Kennedy, Brian; University of Idaho }\end{array}$ \\
\hline Keyword: & $\begin{array}{l}\text { STREAMS < Environment/Habitat, SALMON < Organisms, POPULATION } \\
\text { DYNAMICS < General, BEHAVIOR < General, DISPERSAL < General }\end{array}$ \\
\hline \multicolumn{2}{|l}{} \\
\hline
\end{tabular}

SCHOLARONE ${ }^{\text {m }}$

Manuscripts 
1 Canadian Journal of Fisheries and Aquatic Sciences

2

3 Article

4

5 Juvenile steelhead movements in relation to stream habitat, population density, and body size:

6 consequences for individual growth rates

7

$8 \quad$ Knut Marius Myrvold ${ }^{1 *} ;$ knut.marius.myrvold@gmail.com

$9 \quad$ Brian Patrick Kennedy ${ }^{1,2}$; kennedy@uidaho.edu

10

$11{ }^{1}$ Department of Fish and Wildlife Sciences

$12{ }^{2}$ Department of Biological Sciences and Department of Geological Sciences

13 University of Idaho, Moscow, ID, USA 83844-1136

14

15 * Correspondence author: Knut Marius Myrvold, email: knut.marius.myrvold@gmail.com, phone: +1

16 208-310-2550, fax: +1 208-885-9080

17 Key words: behaviour, dispersal, population dynamics, salmonid, streams 
18

\section{Abstract}

Anadromous salmonids can display considerable movement within their natal streams prior to outmigration, reflecting behavioural responses to biotic and abiotic conditions. Here we quantify dispersal and site fidelity in juvenile steelhead (Oncorhynchus mykiss) over four weeks in fall, their consequences for individual growth rates, and how habitat, density, and individual body size can explain individual movement decisions. Retention rates ranged from $29 \%$ to $66 \%$, and were greater among yearlings (61\%) than subyearlings (31\%). Site fidelity in yearlings was best predicted by individual body mass (negative relationship), and site fidelity in both age classes was positively related to pool habitat availability. An experimental increase in density caused depressed growth rates in both age classes, and site fidelity was lower among translocated fish than among individuals originally residing in the manipulated sites. Within control sites, there were no significant consequences of movement for growth rates in either age class. These results show that movement rates can vary in response to local conditions, and that growth rates in movers can equal or exceed those of sedentary individuals. 


\section{Introduction}

The movements of fishes provide an important ecological link between individual behaviour and the demographics of their populations (Holtby et al. 1990; Begon et al. 1996; Turchin 1998; Fraser et al. 2001), and studies have reported on relatively large contributions of migrants in local populations

(Gowan and Fausch 1996; Rodriguez 2002; Booth et al. 2013). Individual decisions to move are generally motivated by reproduction, access to resources, and evasion from adverse conditions (Sutherland 1983; Gowan and Fausch 2002). On short timescales (hours to weeks), movement is largely driven by access to resources such as food and cover (Booth et al. 2013), which are typically patchily distributed across movement among suitable patches, and often results in aggregations of individuals where conditions are suitable (Fretwell and Lucas 1970; Sutherland 1983; Wiens 2002). relatively high degrees of territoriality, foraging behaviors focused on drifting prey and, for migratory species, tendencies to exhibit fidelity to juvenile rearing habitats. Recent studies have documented considerable movement in several stream fish species across a range of stream environments (Gowan et al. 1994; Fraser et al. 2001; Kahler et al. 2001; Gowan and Fausch 2002; Morissey and Ferguson 2011;

47 Hamann and Kennedy 2012; Booth et al. 2013; Hayes and Thompson 2014). However, as Booth et al.

48 (2013) noted, few studies have investigated movement on relatively small spatial scales for a large portion of the population. Integrating information on individual behaviour with population demographics would be valuable for quantifying the extent of variation in individual movements within

51 a population, understanding the habitat features individuals are associated with, and for identifying the

52 extent to which competitive interactions mediate the use of preferred habitat (Turchin 1998; Gilliam and Fraser 2001; Kahler et al. 2001; Morissey and Ferguson 2011). For example, are individual 
54 characteristics such as body size more important determinants of site fidelity in certain habitats and at 55 certain life stages? To what extent does competition affect individual movement decisions in habitats where fish tend to aggregate for resources versus in poorer quality habitats with less interaction among

57 individuals? In anadromous salmonids, the best known forms of movement are the adult spawning migration, the dispersal of fry following emergence, and the mass outmigration of smolts (Bjornn and Reiser 1991; McCormick et al. 1998; Quinn 2005). Detailed, spatially explicit information on parr (i.e.

61 free swimming juveniles) movements within their natal streams prior to outmigration remains scarce 62 (Kahler et al. 2001). Parr are typically distributed across the entire length of rivers in the summer and 63 fall, which can span a range of abiotic and biotic conditions (Kahler et al. 2001; Gibson 2002; Myrvold 64 and Kennedy 2015a). Because the heterogeneity of these factors can influence important fitness 65 components such as growth and survival, they can also affect individual behaviour (Gowan and Fausch 2002; Einum et al. 2012). For example, Kahler et al. (2001) reported on substantial movement of juvenile

67 salmonids in small streams in Washington, United States in relation to habitat quality and growth

68 potential. Importantly, movers did not suffer lower growth rates than territorial individuals. Hence, 69 identifying the proximate factors that can explain patterns of movement requires examining both

70 individual characteristics and population demographics, as well as the habitat factors they are

71 associated with (Turchin 1998; Gilliam and Fraser 2001; Gresswell and Hendricks 2007; Morissey and 72 Ferguson 2011).

In this study we monitor individually tagged juvenile steelhead (Oncorhynchus mykiss) across seven, 700m stream reaches which spanned gradients of habitats, population densities, and land use 75 impacts in a tributary to the Clearwater River in Idaho, United States. Our first objective is to quantify movement rates both away from the stream reaches, and movement within reaches in relation to an 
77 experimental density manipulation in designated sites within the reaches. Secondly, we assess the 78 consequences of the density manipulation and movement decisions on individual growth rates. We 79 compare the growth rates of fish that exhibited site fidelity (i.e. no movement) to those that moved, and 80 the growth rates of fish in sites affected by the density manipulation to those in control sites. Finally, we 81 investigate how proximate factors pertaining to individual size, local abundance, and habitat factors can 82 explain individual propensities for movement.

84 Materials and methods

85 Study area and population The study was conducted in the $694 \mathrm{~km}^{2}$ Lapwai Creek watershed $\left(46^{\circ} 17^{\prime} \mathrm{N}, 116^{\circ} 44^{\prime} \mathrm{W}\right)$ in Idaho,

87 United States (Figure 1). The watershed exhibits canyon topography typical of the Interior Columbia 88 River plateau, with an elevation gradient from 1530m on Craig Mountain to 237m where Lapwai Creek empties into the Clearwater River. The predominant land use is dry land grain crops, which covers $34 \%$ of the watershed. Coniferous forests cover $29 \%$, and grasslands dominate the steep canyon sides and

91 valley floors (Homer et al. 2007). Mean annual precipitation is $490 \mathrm{~mm}$, with higher amounts falling at

92 higher elevations, primarily from late October through May. The watershed is designated as critical

93 habitat for wild Snake River steelhead (NMFS 2006) and there is no hatchery supplementation. The

94 majority of steelhead presmolts outmigrates from the system during snowmelt in the spring (Hartson

95 and Kennedy 2015).

96 Study design

98 (Figure 1). Each reach totaled 700 stream meters, and was separated into 11 sites which were either

$9950 \mathrm{~m}$ or $100 \mathrm{~m}$ (Figure 2). The length of the sites was informed by prior monitoring of steelhead 
100

101

102

103

104

105

106

107

108

109

110

111

112

113

114

115

116

117

118

119

120

121

122

abundance in the system (Myrvold and Kennedy 2015a). Setting the length at 50m was an intentional effort to balance the scale at which deliberate dispersal would occur while minimizing the error of misidentifying individuals as movers or stayers due to movement within territories. In September 2012 we captured juvenile steelhead and quantified the physical habitat in each site. Following handling as described below, the fish were released back into their respective sites, with one exception: we translocated all the fish caught in sites 100-150 and 150-200 upstream to sites 500-550 and 550-600 (Figure 2). These sites are henceforth referred to as removal (lower density) and addition (higher density) sites, respectively, whereas sites with natural densities are referred to as control sites. Fish caught in sites 500-550 and 550-600 were returned to their respective sites. Fish from the two removal sites were randomized and translocated in equal numbers into the two addition sites. Subsequent analyses of movement accounted for the manipulation. We revisited each study reach 28 days later (October 2012) to record size and location data on all recaptured individuals. Capture data are given in Appendix 1. An individual was identified as exhibiting site fidelity if it was recaptured in the original capture site, and a mover if it was recaptured in another site. For a translocated individual (i.e. one that was caught in a removal site and transplanted into an addition site), site fidelity refers to recapture in the addition site. Mortality was assumed to be zero between September and October. Clearly this is an oversimplification, as mortality tends to be size-dependent and may vary between residents and movers; however, because of the short duration of the study and generally high survival during this period (Hartson and Kennedy 2015) we expect that mortality does not bias the comparison of stream reaches.

The study was conducted prior to the onset of increased flows which begin in late fall (Appendix 2). Higher flows are generally expected to trigger migration in steelhead in the Snake River Basin (Bjornn 1971; Bjornn and Reiser 1991). To test this we interrogated the pass-by Passive Integrated Transponder 
123 (PIT) arrays in the watershed, using the individual tag codes and period between the visits as query

124 parameters in the PTAGIS software (www.ptagis.org). None of the tagged individuals left the Lapwai 125 Creek watershed during this period (Appendix 3). Movement is hence effectively attributed to non126 migratory behaviour in this study.

128 Sampling methods and material

129 Juvenile steelhead data

Single-pass electrofishing was conducted in each site using a Smith-Root LR-24 backpack

131 electroshocker (Smith-Root Inc., Washington, USA). Prior to any handling we anesthetized the fish with

132 tricaine methanesulfonate (MS-222). We scanned individuals for PIT tags using a FS-2001F-ISO reader

133 (Destron Fearing, Minnesota, USA), noted its capture location, and measured fork length in millimeters

134 and weight to the nearest decigram. All data were recorded in program P3 (PIT-Tag Information System

135 for the Columbia River Basin). In individuals $65 \mathrm{~mm}$ and larger we inserted $134.2 \mathrm{kHz}$ PIT tags (Biomark

136 Inc., Idaho, USA) into the ventral body cavity (referred to as tagable individuals). Following handling, fish

137 were first allowed to recover in buckets with aerated water, and then distributed back into the central

138 location of the site (i.e. the central $30 \mathrm{~m}$ in a $50 \mathrm{~m}$ site). All sampling and handling procedures were

139 permitted as part of the Section 7 consultation for the Lewiston Orchards Biological Opinion (NMFS

140 2006), and reviewed by the Idaho Department of Fish and Game and the University of Idaho Institutional

141 Animal Care and Use Committee. We used the number of steelhead per $100 \mathrm{~m}^{2}$ in September (following

142 the experimental manipulation), natural log-transformed, as the density metric in the modeling. Specific

143 growth rates for recaptured individuals were expressed as percent change in body mass per day

144 between capture and recapture.

145 Correction for capture inefficiency 
147 underestimated the true number of fish present. We introduced a simple correction for this by estimating the true abundance (denoted adjusted numbers in Table 1) based on prior monitoring data in the Lapwai Creek watershed (Myrvold and Kennedy 2015a). The linear relationship used to adjust for capture inefficiency for tagged individuals on the October visit in site $i$ was

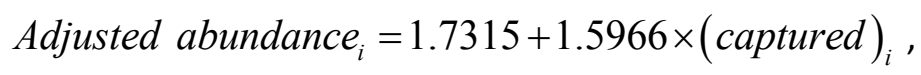

where captured is the number of steelhead caught during the single-pass electrofishing effort (ordinary least squares; $\left.r^{2}=0.93, F=1308, N=103, d . f .=102, p<0.0001\right)$. Further details are given in Appendix 4. Habitat data

A habitat assessment (Fisher et al. 2012) was conducted in each site to quantify the habitat. The site was categorized into channel geomorphic units (pool, riffle, glide, and run) based on the prevailing

157 habitat features along the channel thalweg. We recorded the length of each unit $(\mathrm{m})$, its maximum 158 depth $(\mathrm{cm})$, lengths of overhanging vegetation and undercut banks of the unit $(\mathrm{m})$, and the number of 159 large woody debris pieces (count). For standardization among sites we calculated the following metrics 160 to be used in the modeling: proportion of each channel geomorphic unit, proportion of each site with 161 overhanging vegetation and/or undercut banks, the number of large woody debris pieces per stream 162 meter, the average depth of the site, and the standard deviation of the depth measurements in the site 163 (a metric that indicates depth heterogeneity). Characteristics of these metrics are given in Table 2.

165 Statistical analyses

166 Movement and growth rates - objectives 1 and 2 manipulation. To study whether the treatment had an effect on site fidelity across all reaches, we first 
analyzed the adjusted site fidelity by treatment category using the Cochran-Mantel-Haenszel Chi-square test in SAS 9.2 Proc FREQ (SAS Institute, North Carolina, USA). We also investigated whether stream reach had an effect on site fidelity (i.e. does the reach in which the individuals reside affect the proportion of the individuals that exhibit site fidelity). We specified a log-linear Poisson model in SAS Proc GENMOD where stream reach was included as an interacting factor with treatment category, and adjusted the analysis for multiple comparisons.

Secondly, we quantified the effects of the density treatment and the consequences of decisions to stay or move on individuals growth rates. We analyzed differences in average growth rates 1) between treatment categories for fish that exhibited site fidelity to these sites; 2 ) between movers and non-movers in the control sites; and 3) as a function of movement direction and distance (number of units moved). We performed one-way analyses of variance to compare the means using SAS Proc ANOVA and SAS Proc TTEST.

Site fidelity models - objective 3

We investigated whether certain proximate factors (individual body size, density, and habitat) could explain an individual's propensity to exhibit site fidelity. We specified a set of mixed effects logistic regression models to model individual site fidelity while accounting for correlation among individuals residing in the same site (Table 3). Because preferences and behaviour differ between the age classes (Bjornn and Reiser 1991; Rosenfeld and Boss 2001) we modeled the age classes separately. The mixed effects logit model (Allison 2012) for individual $i$ in site $j$, with one individual-level predictor variable $x$ and a site-specific intercept can be expressed as

$$
\ln \left[\frac{p_{i j}}{1-p_{i j}}\right]=\beta_{0 \mathrm{j}}+\beta_{10} x_{i j} \text { (eq. 1) }
$$


190

191

192

193

194

195

Because the sites were sampled at random from a larger population of possible sites, we can assume

that

where $\gamma_{00}$ is the grand mean intercept, and $u_{0 j}$ is a deviation from that mean, which is iid $N\left(0, \sigma^{2}\right)$.

Substituting into equation 1 , the mixed effects logit model becomes

$$
\ln \left[\frac{p_{i j}}{1-p_{i j}}\right]=\gamma_{00}+\gamma_{10} x_{i j}+u_{0 j} \text { (eq. 2) }
$$

196

Secondly, we tested whether site-level factors such as habitat characteristics and local density could influence an individual's propensity to stay in the site. In the case where we did not include any individual-level covariates, a random intercept model relating the log-odds of fish $i$ in site $j$ staying as a

199 function of a site-level covariate $Z$ can be written as

$$
\ln \left[\frac{p_{i j}}{1-p_{i j}}\right]=\gamma_{00}+\gamma_{01} Z_{j}+u_{o j} \text { (eq. 3), }
$$

where $u_{0 j} \sim N\left(0, \tau_{00}\right)$, and $\tau_{00}$ is the residual variance after controlling for $Z$.

Thirdly, we considered both individual-level and site-level predictors, with a random intercept

203

for each site. The intercept in equation 1 can be written as a linear combination of a grand mean, a site fixed effect, and site random effects, whereas the slope parameter remains unchanged:

$$
\ln \left[\frac{p_{i j}}{1-p_{i j}}\right]=\gamma_{00}+\gamma_{01} Z_{j}+\gamma_{10} x_{i j}+u_{0 j} \text { (eq. 4) }
$$




$$
\ln \left[\frac{p_{i j}}{1-p_{i j}}\right]=\gamma_{00}+\gamma_{01} Z_{j}+\gamma_{10} x_{i j}+\gamma_{11} x_{i j} Z_{j}+u_{0 j} \text { (eq. 5), }
$$

with the same general properties as above. We used SAS Proc GLIMMIX with a logit-link function and binary distribution for the response; the containment method for calculating the denominator degrees

211 of freedom; and maximum likelihood estimation with a Gauss-Hermite quadrature approximation

212 (Lange 1999; SAS Institute 2008; Allison 2012). The variance inflation factors for the covariates included 213 in the models were $<1.5$, indicating no issues with multicollinearity. All models, except the best

214 subyearling model, proved statistically significant $(p<0.05)$ for the random intercept using the mixture

215 likelihood ratio chi-square test, which means that the random effects structure was appropriate (SAS

216 Institute 2008b). Although the subyearling model was not statistically significant $(p=0.37)$, analyzing it

217 under an ordinary logistic regression framework would largely violate the assumptions of independence

218 among subjects. For all models, the ratio of the Pearson Chi-square over the degrees of freedom was

219 within $10 \%$ of 1.00, which meant there were no problems with overdispersion (SAS Institute 2008). We

220 checked that model assumptions were met by examining their residual plots using the ods graphics

221 option in SAS (SAS Institute 2008). Model structures are shown in Table 3.

We used Akaike's information criterion $(A I C)$ to assess the relative plausibility of the candidate

223 models (Akaike 1973; Burnham and Anderson 2002). Within each cohort we provided parameter

224 estimates for models with substantial relative support, i.e. models with AIC scores within 2.0 points of

225 the model with lowest score (Burnham and Anderson 2002).

227 Results

228 Movement rates and site fidelity - objective 1 
We tagged 533 subyearling and 811 yearling steelhead at the beginning of the study, and recaptured 103 and 310 individuals, respectively (unadjusted numbers). Adjusted for capture inefficiency, these numbers were estimated at 166 (31\%) and 497 (61\%), respectively. The adjusted retention of individuals within their respective $700 \mathrm{~m}$ reaches averaged $50 \%$ (SD=15\%), and varied from $29 \%$ to $66 \%$ across the seven stream reaches (Table 1 ). However, not all of these exhibited fidelity to the site in which they were caught to which they were translocated. The overall adjusted site fidelity averaged $40 \%(S D=13 \%)$ and varied from $21 \%$ to $59 \%$ among the stream reaches. detected 74 at the local PIT tag arrays. The majority of these (69 out of the 74) were detected at the arrays on the mouth of the stream in which they were tagged, and the rest ( 5 of the 74 ) were also detected at one downstream array (Figure 1; Appendix 2). However, none of the PIT-tagged fish left the Lapwai Creek watershed during the study, i.e. they were not detected at the array at the mouth of Lapwai Creek. This shows that fish were primarily moving within their natal streams rather than 242 beginning an outmigration.

We analyzed the adjusted site fidelity by treatment category, and whether rates differed among 244 stream reaches. Site fidelity differed significantly between treatment categories (Cochran-Mantel245 Haenszel general association statistic $=11.93, N=1344, d . f .=2, p=0.0026)$. Adjusted site fidelity among 246 fish originally residing in addition sites (i.e. fish that were not translocated, but that experienced the 247 elevated densities) was 58\% (123/213); for translocated fish site fidelity was 23\% (35/150); and in 248 control sections site fidelity was 39\% (379/981) (Figure 3). There was also a significant influence of 249 stream reach (likelihood-ratio statistics for the site fidelity $\times$ stream reach interaction $=59.91, N=42$, $250 d . f .=6, p<0.0001)$, which indicate that rates of site fidelity differed among stream reaches. These results 251 show that movement rates increased at higher densities, but primarily among translocated individuals. 
We could not determine the origin of all the fish moving into the vacant habitat in the removal

253 sites, i.e. whether they were individuals present in the reach in September but not captured and tagged,

254 or originating from outside the reach, hence untagged. However, among the tagged fish that were

255 recaptured in October, fish in control sites moved into the removal sites at a higher rate than into other

256 control sites (Figure 3). Whereas 12 fish moved into the removal sites, 33 moved into other control sites,

257 which covered approximately a five times larger area. This corresponds to a 1.7 times higher rate of

258 movement into vacant habitat in removal sites than into other control sites.

259 Effects on growth rates - objective 2

We found significant differences in growth rates among the removal, addition, and control sites

261 for both age classes of juvenile steelhead (Table 4, top panel). Here we compared the growth rates of

262 individuals exhibiting site fidelity in the respective treatment category, i.e. the solid lines in Figure 3.

263 Importantly, fish that had been added to or remained in the addition sites experienced elevated

264 densities relative to fish in the control sites. In subyearlings, average growth rates were significantly

265 lower in fish originally residing in addition sites than in fish from the other two treatment categories

266 (Figure 4a; ANOVA; $F=3.12, N=88, d . f .=87, p=0.049$ ). Compared to natural conditions, subyearlings

267 originally residing in addition sites responded negatively to the increased density but translocated

268 individuals did not appear to suffer the same consequences. Density had a more direct impact on

269 growth in yearling steelhead. Yearling growth rates were lower among fish experiencing the elevated

270 densities in addition sites than in control sites (Figure 4b; ANOVA; $F=4.09, N=247, d . f .=246, p=0.018$ ).

271 Within the control sites, there were no statistically significant consequences of site fidelity vs.

272 movement for growth rates in either age class (Table 4). Although subyearlings that moved into vacant

273 habitat in the removal sites achieved a higher average growth rate than those moving to other control

274 sites, the difference was nonsignificant at the $\alpha=0.05$-level (ANOVA; $F=1.70, N=81, d . f .=80, p=0.19$ ). No 
275 subyearlings moved into addition sites. Similarly, for yearlings, the average growth rates showed no

276 statistical difference (ANOVA; $F=0.76, N=206$, d.f. $=205, p=0.52$ ).

277 For the 78 recaptured individuals that moved there were no effects of the number of units

278 moved (ANOVA; $F=0.74, N=78, d . f .=77, p=0.67$ ) or the direction of movement (i.e. upstream or

279 downstream, $t$-test with unequal variances and Satterthwaite approximation; $t=-0.68, N=78, d . f .=53$,

$280 p=0.50)$ on their growth rates.

281 Determinants of site fidelity - objective 3

282 A model including habitat variables reflecting stream channel complexity (model $6 ; w_{i}=0.35$ )

283 best explained subyearling site fidelity (Table 5). The model included variables whose confidence

284 intervals overlapped zero, which warrants careful interpretation. However, the results indicate that

285 subyearlings were more likely to stay in sites with higher proportions of pool habitat and undercut

286 banks, and less woody debris and depth variation.

287

For yearling steelhead, four models (models $1,6,10$, and 11) received substantial relative

support ( $88 \%$ combined) (Table 3). The best approximating model, model 10, predicted higher odds of

289 site fidelity with smaller individual body mass and increased proportion of pool habitat in the site.

290 Individual body mass appeared to be important in three out of the four best models, with declining odds

291 of site fidelity with increasing mass, either as a sole predictor (model 1) or together with proportion of

292 pool habitat (models 10 and 11). Proportion pool habitat also appeared to be an important predictor of

293 site fidelity in yearlings, showing a positive relationship between site fidelity and pool abundance (Table

$2945)$.

295

296 Discussion 
298 large fraction of the juvenile steelhead population was mobile, with some local variation in relation to 299 biotic factors and abiotic conditions. We detected only a small fraction of the movers at our PIT antennae, located at the mouth of the tributaries, which shows that individuals were primarily moving 301 within their natal streams. Theory predicts that animals will distribute themselves according to the 302 relative profitability of habitat patches, whereby access to food and shelter is weighed against the competition for those resources (Fretwell and Lucas 1970; Sutherland 1983; but see Tregenza 1995). For

304 fish to obtain information on neighboring patches it hence necessitates exploratory movement at the 305 scale of stream reaches (Gowan et al. 1996; Gowan and Fausch 2002).

A number of studies have investigated the causes and consequences of non-migratory movement in stream salmonids across a variety of stream ecosystems. Gowan and Fausch (2002) found that brook trout (Salvelinus fontinalis) in high elevation streams exhibited substantial movement in the summer. Their findings indicated that individuals moved around at the scale of hundreds of meters to monitor habitat conditions in the reach, and to access resources as these changed over time. In a study

311 in small streams in Western Washington, Kahler et al. (2001) documented considerable movement of 312 coho salmon (O. kisutch) and other salmonids over the summer. Coho movers were similar in size as 313 sedentary individuals, contrary to what would be expected if movement was solely the result of 314 competition over space (Abbott et al. 1985), and they also grew faster than their sedentary 315 counterparts. Kahler et al. concluded that movement reflects habitat choice and that movers were not 316 competitively inferior to sedentary individuals. In a tributary to the Salmon River in Idaho, Bjornn (1971)

317 found that many juvenile steelhead redistributed in a downstream direction in preparation for the 318 winter season. These movements occurred as the temperature was decreasing but remained above 12 $319{ }^{\circ} \mathrm{C}$, flows were stable, and prey in the drift were still relatively abundant. Bjornn (1971) postulated that 
this behaviour was a local adaptation to seek out habitat more suitable during winter conditions,

321 presumably cued by changes in temperature and photoperiod.

323 habitats and a potential competitive advantage over subyearlings (Bjornn and Reiser 1991; Myrvold and

324 Kennedy 2015b). Both age classes can show preferences for pool habitats in summer and fall, but inter-

325 cohort competition may preclude subyearlings from gaining access to preferred habitats (Bjornn and

326 Reiser 1991; Chun et al. 2011). Competition for space is usually asymmetric in age-structured

327 populations, whereby older and larger individuals can dominate smaller individuals (Abbott et al. 1985;

328 Rosenfeld and Boss 2001; Kaspersson and Höjesjö 2009). For example, Rosenfeld and Boss (2001)

329 removed large cutthroat trout (O. clarkii) and found that smaller individuals moved into the vacant,

330 preferred habitat from which they had previously been competitively displaced. In addition to the direct

331 effects of habitat on site fidelity (the selection for habitat features), habitat configuration can also

332 mediate competition between age classes (Höjesjö et al. 2004; Kaspersson et al. 2013). Höjesjö et al.

333 (2004) found that the adverse effects of aggressive behaviour from dominant brown trout (Salmo trutta)

334 on growth in subordinate individuals decreased with increased habitat complexity. Hence, with pools

335 typically offering more structure than other channel unit types, their effects on site fidelity could

336 therefore owe to both habitat selection and less competition. Taken together, individual movement

337 decisions might therefore represent a trade-off between competition and microhabitat preferences

338 (Hughes and Dill 1990; Railsback et al. 1999; Gowan and Fausch 2002).

Our sample size may have been insufficient to detect statistically significant differences in

340 growth rates between movers and non-movers in sites with natural densities. Although the differences

341 were not statistically significant, yearlings that moved to other control sites (average $0.23 \%$ body mass

342 per day) grew faster than non-movers remaining in control sections (average $0.16 \%$ ). This is similar to 
343 the finding by Kahler et al. (2001). However, subyearlings showed the opposite trend. Sedentary

344 subyearlings grew faster (average $0.87 \%$ ) than the individuals moving into other control sections

345 (average 0.59\%). These differences are relatively large if one considers their ramifications throughout

346 the juvenile stage, and may influence lifetime fitness components (Holtby et al. 1990). The ideal free

347 distribution predicts relatively equal growth among habitat patches because animals will distribute

348 themselves according to resource availability (Fretwell and Lucas 1970; Sutherland 1983). However, this

349 prediction holds only if individuals have equal competitive abilities, an assumption that might be unlikely

350 for stream salmonids whose individual differences can be substantial (Tregenza 1995; Kaspersson and

351 Höjesjö 2009; Myrvold and Kennedy 2015b).

Recent studies have shown that body size differences within an age class can ultimately result

353 from individual differences in behaviour and physiology (Reid et al. 2011; Adriaenssens and Johnsson

354 2013), whereby individuals exhibiting higher standard metabolic rates and greater boldness can

capitalize on greater feeding opportunities because they displace subordinate individuals or gain access

to new habitat. Our study did not examine variation in individual characteristics other than body mass. It

357 therefore remains unclear whether the variation in size and site fidelity was the result of differences in

358 personality traits or hormonal levels. A previous study in the same population found that the energetic

359 cost incurred by high water temperatures in the summer represented a bottleneck to growth in

360 sedentary individuals (Myrvold and Kennedy 2015c). Defending territories can represent a significant

361 expense during energetically stressful conditions, which would suggest that a non-territorial movement

362 tactic could increase energy allocation towards growth (Myrvold and Kennedy 2015c). Following a dam

363 modification in Washington, Anderson et al. (2008) found that juvenile coho salmon dispersed upstream

364 of adult spawning locations, hence contributing to colonization of newly accessible habitat. The movers

365 were slightly larger than the nonmovers, which is similar to the results of this study. We found that site 
fidelity in yearlings was negatively related to body mass. We cannot determine whether this suggests

367

368

369

371

372

373

374

375

376

377

378

379

380

381

382

383

that exploratory boldness (as indicated by lower site fidelity) confers a growth advantage. However, in absence of movement related to smoltification in yearlings, it could provide an explanation for the sizesite fidelity relationship.

Translocated fish exhibited lower site fidelity than individuals originally residing in the additionand control sites (Figure 3). We could not determine the extent to which this owed to the density treatment directly (i.e. increased competition) or that these individuals were removed from their home ranges (i.e. unfamiliar habitat). We found evidence of depressed growth in both subyearling and yearling steelhead originally residing in the addition sites relative to control sites. This suggests that the density treatment had a direct effect on their growth rates, which corresponds with previous research on the consequences of density dependence for individual growth (Jenkins et al. 1999; Keeley 2001; Myrvold and Kennedy 2015b). However, these fish also exhibited the highest site fidelity. Among fish in control sites, we detected a higher rate of movement into removal sites (i.e. with lower densities) than into other control sites and addition sites. With less competition for food and space in removal sites, this is an expected result and suggests that steelhead monitor the competition for resources as well as the quantity and quality of those resources (Anderson et al. 2008). It is therefore likely that the lower site fidelity in translocated fish could be attributed to a combination of elevated densities and unfamiliar habitat.

We did not estimate individual home ranges, as our primary objective was to quantify rates of movement in relation to individual size and stream site characteristics. Because movement was recorded as binary (stay or move) it could be the case that individuals occupying territories close to the border between sites could be misidentified as movers or stayers, depending on within-territory position at the time of sampling or evasion due to sampling (Albanese et al. 2003). However, it is 
unlikely that it biased the results. First, it is unlikely that there were any behavioural differences between individuals in the center vs. the edge of sites because the reaches were placed in a random manner. The probability of correctly assigning individuals whose territories straddled two sites would equal that of wrongly assigning the individual to a site. Because the reverse is true for assigning it to the adjacent site, we can assume that these directional errors cancel each other. Secondly, we focused on the main effects of individual movement and growth in relation to the density manipulation and site characteristics for a large sample of individuals. It is hence unlikely that any misidentification could influence the observed effects to an extent capable of shifting the direction and magnitude of the 397 movement rates. movement. Whereas some have documented the majority of the population exhibiting strong site fidelity at the scale of a few meters (Heggenes et al. 1991; Steingrimsson and Grant 2003), others have found that movement on the scale of several channel units to kilometers for most of the individuals in the population is the rule rather than the exception (Gowan et al. 1994; Young 1994; Kahler et al. 2001;

403 Morissey and Ferguson 2011). Research to date suggests that movers are not necessarily "losers" in 404 terms of growth and survival (e.g Kahler et al. 2001; Anderson et al. 2008), and may simply represent 405 optimal foraging on the short term (Gowan and Fausch 2002) or a different life history tactic relative to 406 territorial behaviour on the long term (Quinn 2005). Whether mobility relative to site fidelity ultimately 407 contributes to population demographic rates depends on a multitude of other factors (Holtby et al. 408 1990; Gowan and Fausch 2002; Quinn 2005), however, in the context of population resilience a diverse 409 array of life-history tactics increases its adaptive potential (Quinn 2005; Moore et al. 2014). We believe 410 this is represents an interesting question for future research, especially with regards to adaptive 
411 potential during rapidly changing thermal and hydrologic regimes (Deiner et al. 2007; Adriaenssens and 412 Johnsson 2013). 


\section{Acknowledgments}

414 This work was funded by the United States Bureau of Reclamation, University of Idaho Waters of 415 the West Program, and United States Geological Survey. Special thanks go to K. Rützel for invaluable 416 help designing the experiment. We thank E. Benson, J. Caisman, and R. Hartson for tremendous help

417 obtaining the field data; three anonymous reviewers for their insightful comments on the manuscript;

418 Lewiston Orchards Irrigation District, Nez Perce Tribe, and landowners for access to their properties; and 419 finally friends and colleagues for help and support throughout the project. 


\section{References}

422 Abbott, J.C., Dunbreck, R.L., and Orr, C.D. 1985. The interaction of size and experience in dominance 423 relationships of juvenile steelhead trout (Salmo gairdneri). Behaviour 92:241-253.

424 Adriaenssens, B., and Johnsson, J.I. 2013. Natural selection, plasticity and the emergence of a 425 behavioural syndrome in the wild. Ecol. Lett. 16: 47-55.

426 Akaike, H. 1973. Information theory and an extension of the maximum likelihood principle. In Second

427 International Symposium on Information Theory. Edited by B.N. Petrov and F. Csaki. Akademiai Kiado, 428 Budapest, Hungary. pp. 267-281.

429 Albanese, B., Angermeier, P.L., and Gowan, C. 2003. Designing mark-recapture studies to reduce effects 430 of distance weighting on movement distance distributions of stream fishes. Trans. Am. Fish. Soc. 132:

$431925-939$.

432 Allison, P.D. 2012. Logistic regression using SAS: theory and application. SAS Institute, Cary, NC.

433 Anderson, J.H., Kiffney, P.M., Pess, G.R., and Quinn, T.P. 2008. Summer distribution and growth of

434 juvenile coho salmon during colonization of newly accessible habitat. Trans. Am. Fish. Soc. 137: 772435781.

436 Begon, M., Harper, J.L., and Townsend, C.R. 1996. Ecology: individuals, populations and communities.

437 Blackwell Science, Cambridge, MA.

438 Bjornn, T.C. 1971. Trout and salmon movements in two Idaho streams as related to temperature, food, 439 stream flow, cover, and population density. Trans. Am. Fish. Soc. 100: 423-438.

440 Bjornn, T.C., and Reiser, D.W. 1991. Habitat requirements of salmonids in streams. In Influences of

441 forest and rangeland management on salmonid fishes and their habitat. Edited by W.R. Meehan.

442 American Fisheries Society Special Publication 19, Bethesda, MD. pp. 83-138. 
443

444

445

446

447

448

449

450

451

452

453

454

455

456

457

458

459

460

461

462

463

464
Booth, M.T., Hairston, N.G., and Flecker, A.S. 2013. How mobile are fish populations? Diel movement, population turnover, and site fidelity in suckers. Can. J. Fish. Aquat. Sci. 70: 666-677.

Burnham, K.P., and Anderson, D.R. 2002. Model selection and multimodel inference: A practical information-theoretic approach. Springer, New York, NY.

Chun, S.N., Cocherell, S.A., Cocherell, D.E., Miranda, J.B., Jones, G.J., Graham, J., Klimley, A.P., Thompson, L.C., and Cech Jr., J.J. 2011. Displacement, velocity preference, and substrate use of three native California stream fishes in simulated pulsed flows. Environ. Biol. Fishes 90: 43-52.

Deiner, K., Garza, J.C., Coey, R., and Girman, D.J. 2007. Population structure and genetic diversity of trout (Oncorhynchus mykiss) above and below natural and man-made barriers in the Russian River, California. Conserv. Genet. 8: 437-454.

Einum, S., Finstad, A.G., Robertsen, G., Nislow, K.H., McKelvey, S., and Armstrong, J.D. 2012. Natal movement in juvenile Atlantic salmon: a body size-dependent strategy? Popul. Ecol. 54: 285-294.

Einum, S., Sundt-Hansen, L., and Nislow, K.H. 2006. The partitioning of density-dependent dispersal, growth and survival throughout ontogeny in a highly fecund organism. Oikos 113: 489-496.

Fisher, W.L., Bozek, M.A., Vokoun, J.C., and Jacobson, R.B. 2012. Freshwater aquatic habitat measurements. In Fisheries techniques, 3rd edition. Edited by A.V. Zale, D.L. Parrish, and T.M. Sutton. American Fisheries Society, Bethesda, MD. pp. 101-161.

Fraser, D.F., Gilliam, J.F., Daley, M.J., Le, A.N., and Skalski, G.T. 2001. Explaining leptokurtic movement distributions: interpopulation variation in boldness and exploration. Am. Nat. 158: 124-135.

Fretwell, S.D., and Lucas, H.L. 1970. On territorial behaviour and other factors influencing habitat distribution in birds. Acta Biotheor. 19: 16-36.

Gerking, S.D. 1959. The restricted movement of fish populations. Biol. Rev. 34: 221-242. 
465

466

467

468

469

470

471

472

473

474

475

476

477

478

479

480

481

482

483

484

485

486

487

Gibson, R.J. 2002. The effects of fluvial processes and habitat heterogeneity on distribution, growth and densities of juvenile Atlantic salmon (Salmo salar L.), with consequences on abundance of the adult fish. Ecol. Freshw. Fish 11: 207-222.

Gilliam, J.F., and Fraser, D.F. 2001. Movement in corridors: enhancement by predation threat, disturbance, and habitat structure. Ecology 82: 258-273.

Gowan, C., and Fausch, K.D. 1996. Long-term demographic responses of trout populations to habitat manipulation in six Colorado streams. Ecol. Appl. 6: 931-946.

Gowan, C., and Fausch, K.D. 2002. Why do foraging stream salmonids move during summer? Environ. Biol. Fishes 64: 139-153.

Gowan, C., Young, M.K., Fausch, K.D., and Riley, S.C. 1994. Restricted movement in resident stream salmonids: a paradigm lost? Can. J. Fish. Aquat. Sci. 51: 2626-2637.

Gresswell, R.E., and Hendricks, S.R. 2007. Population-scale movement of coastal cutthroat trout in a naturally isolated stream network. Trans. Am. Fish. Soc. 136: 238-253.

Hamann, E.J., and Kennedy, B.P. 2012. Juvenile dispersal affects straying behaviors of adults in a migratory population. Ecology 93: 733-740.

Hartson, R.B., and Kennedy, B.P. 2015. Competitive release modifies the impacts of hydrologic alteration for a partially migratory stream predator. Ecol. Freshw. Fish 24: 276-292.

Hayes, D. B., and B. E. Thompson. 2014. Movement rules for juvenile steelhead: dynamic linking of movement behaviour to habitat and density. Ecol. Freshw. Fish 23: 581-593

Heggenes, J., Northcote, T.G., and Peter, A. 1991. Spatial stability of cutthroat trout (Oncorhynchus clarki) in a small, coastal stream. Can. J. Fish. Aquat. Sci. 48: 757-762.

Höjesjö, J., Johnsson, J., and Bohlin, T. 2004. Habitat complexity reduces the growth of aggressive and dominant brown trout (Salmo trutta) relative to subordinates. Behav. Ecol. Sociobiol. 56: 286-289. 
488 489 490

491 492 493 494 495 496 497 498 499 500 501 502 e62157.

503 504 505 506 507 508 509 510

Holtby, L.B., Andersen, B.C., and Kadowaki, R.K. 1990. Importance of smolt size and early ocean growth to interannual variability in marine survival of coho salmon (Oncorhynchus kisutch). Can. J. Fish. Aquat. Sci. 47: 2181-2194.

Homer, C., Dewitz, J., Fry, J., Coan, M., Hossain, N., Larson, C., Herold, N., McKerrow, A., VanDriel, J.N., and Wickham, J. 2007. Completion of the 2001 National Land Cover Database for the conterminous United States. Photogramm. Eng. Remote Sensing 73: 337-341.

Jenkins Jr., T.M., Diehl, S., Kratz, K.W., and Cooper, S.D. 1999. Effects of population density on individual growth of brown trout in streams. Ecology 80: 941-956.

Kahler, T.H., Roni, P., and Quinn, T.P. 2001. Summer movement and growth of juvenile anadromous salmonids in small western Washington streams. Can. J. Fish. Aquat. Sci. 58: 1947-1956.

Kaspersson, R., and Höjesjö, J. 2009. Density-dependent growth rate in an age-structured population: a field study on stream-dwelling brown trout Salmo trutta. J. Fish Biol. 74: 2196-2215.

Kaspersson, R., Sundström, F., Bohlin, T., and Johnsson, J. 2013. Modes of competition: adding and removing brown trout in the wild to understand the mechanism of density dependence. PLoS One 8(5):

Keeley, E.R. 2001. Demographic responses to food and space competition by juvenile steelhead trout. Ecology 82: 1247-1259.

Lange, K. 1999. Numerical analysis for statisticians. Springer, New York, NY. McCormick, S.D., Hansen, L.P., Quinn, T.P., and Saunders, R.L. 1998. Movement, migration, and smolting of Atlantic salmon (Salmo salar). Can. J. Fish. Aquat. Sci. 55: 77-92.

Moore, J.W., Yeakel, J.D., Peard, D., Lough, J., and Beere, M. 2014. Life-history diversity and its importance to population stability and persistence of a migratory fish: steelhead in two large North American watersheds. J. Anim. Ecol. 83:1035-1046. 
511 Morissey, M.B., and Ferguson, M.M. 2011. Individual variation in movement throughout the life cycle of

512 a stream-dwelling salmonid fish. Mol. Ecol. 20: 236-248.

513 Myrvold, K.M., and Kennedy, B.P. 2015a. Variation in juvenile steelhead density in relation to intream

514 habitat and watershed characteristics. Trans. Am. Fish. Soc. 144: 577-590.

515 Myrvold, K.M., and Kennedy, B.P. 2015b. Density dependence and its impact on individual growth rates

516 in an age-structured stream salmonid population. Ecosphere 6: 281.

517 Myrvold, K.M., and Kennedy, B.P. 2015c. Interactions between body mass and water temperature cause 518 energetic bottlenecks in juvenile steelhead. Ecol. Freshw. Fish 24: 373-383.

519 NMFS. 2006. Endangered Species Act - section 7 formal consultation Biological Opinion and Magnuson-

520 Stevens Fishery Conservation Act Essential Fish Habitat consultation for the operation and maintenance

521 of the Lewiston Orchards Project. National Marine Fisheries Service, Seattle, WA.

522 Quinn, T.P. 2005. The behavior and ecology of Pacific salmon and trout. American Fisheries Society in 523 association with University of Washington Press, Bethesda, MD.

524 Railsback, S.F., Lamberson, R.H., Harvey, B.C., and Duffy, W.E. 1999. Movement rules for individual-

525 based models of stream fish. Ecol. Modell. 123: 73-89.

526 Reid, D., Armstrong, J.D., and Metcalfe, N.B. 2011. Estimated standard metabolic rate interacts with

527 territory quality and density to determine the growth rates of juvenile Atlantic salmon. Funct. Ecol. 25:

$528 \quad 1360-1367$.

529 Rodriguez, M.A. 2002. Restricted movement in stream fish: the paradigm is incomplete, not lost. Ecology

530 83: 1-13.

531 Rosenfeld, J.S., and Boss, S. 2001. Fitness consequences of habitat use for juvenile cutthroat trout:

532 energetic costs and benefits in pools and riffles. Can. J. Fish. Aquat. Sci. 58: 585-593.

533 SAS. 2008. SAS/STAT 9.2 User's guide: The GLIMMIX procedure. SAS Institute, Cary, NC. 
534 Steingrimsson, S.O., and Grant, J.W.A. 2003. Patterns and correlates of movement and site fidelity in 535 individuall tagged young-of-the-year Atlantic salmon (Salmo salar). Can. J. Fish. Aquat. Sci. 60: 193-202.

536 Sutherland, W.J. 1983. Aggregation and the "ideal free" distribution. J. Anim. Ecol. 52: 821-828.

537 Turchin, P. 1998. Quantitative analysis of movement. Sinauer Associates, Sunderland, MA.

538 Wiens, J.A. 2002. Riverine landscapes: taking landscape ecology into the water. Freshw. Biol. 47: 501539515.

540 Young, M.K. 1994. Brown trout mobility in south-central Wyoming streams. Can. J. Zool. 72: 2078-2083. 541 
542 Tables

543 
544 Table 1

545 Table 1. Distribution of all PIT-tagged steelhead by treatment category. The left panel shows the total numbers tagged, retained in the stream

546 reach, and exhibiting site-fidelity with percentages of the number tagged in parentheses. The next panels show these numbers partitioned by

547 treatment category for each study site. $A$ refers to sites to which fish were added, $R$ to sites from which fish were removed, and $O$ to control sites

548 with no density treatment. Unadjusted numbers refer to the actual catch; adjusted numbers refer to the estimated numbers of tagged fish if our

549 capture probability would have been 1.00 .

\begin{tabular}{|c|c|c|c|c|c|c|c|c|c|c|c|c|}
\hline \multirow[b]{3}{*}{ Reach } & \multirow{2}{*}{\multicolumn{3}{|c|}{ Totals }} & \multicolumn{3}{|c|}{ Tagged fish, } & \multicolumn{3}{|c|}{ Fish retained in } & \multicolumn{3}{|c|}{ Fish exhibiting site } \\
\hline & & & & \multicolumn{3}{|c|}{ September } & \multicolumn{3}{|c|}{ stream reach } & \multicolumn{3}{|c|}{ fidelity } \\
\hline & Tagged & Retained & Site fidelity & $A$ & $R$ & 0 & $A$ & $\mathrm{R}$ & 0 & $A$ to $A$ & $\mathrm{R}$ to $\mathrm{A}$ & 0 to \\
\hline \multicolumn{13}{|c|}{ Unadjusted numbers } \\
\hline LSX & 82 & $14(17 \%)$ & $11(13 \%)$ & 9 & 14 & 59 & 0 & 1 & 13 & 0 & 0 & 11 \\
\hline MLX & 142 & $32(23 \%)$ & $27(19 \%)$ & 12 & 17 & 113 & 2 & 4 & 26 & 2 & 3 & 22 \\
\hline ULU & 244 & $100(41 \%)$ & $89(36 \%)$ & 80 & 2 & 162 & 45 & 0 & 55 & 39 & 0 & 50 \\
\hline UMU & 187 & $63(34 \%)$ & $48(26 \%)$ & 29 & 20 & 138 & 13 & 6 & 44 & 10 & 4 & 34 \\
\hline USM & 213 & 76 (36\%) & $63(30 \%)$ & 28 & 29 & 156 & 8 & 9 & 59 & 7 & 9 & 47 \\
\hline USU & 184 & 75 (41\%) & $59(32 \%)$ & 23 & 23 & 138 & 14 & 9 & 52 & 14 & 4 & 41 \\
\hline
\end{tabular}




\begin{tabular}{|c|c|c|c|c|c|c|c|c|c|c|c|}
\hline UWM & 292 & $53(18 \%)$ & 38 (13\%) & 32 & 45 & 215 & 4 & 11 & 38 & 4 & 2 \\
\hline SUM & 1344 & 413 (31\%) & 335 (25\%) & 213 & 150 & 981 & 86 & 40 & 287 & 76 & 22 \\
\hline
\end{tabular}

Adjusted numbers

$\begin{array}{lllllllllllll}\text { LSX } & 82 & 24(29 \%) & 19(24 \%) & 9 & 14 & 59 & 2 & 3 & 22 & 2 & 2 & 19 \\ \text { MLX } & 142 & 53(37 \%) & 45(32 \%) & 12 & 17 & 113 & 5 & 8 & 43 & 5 & 7 & 37 \\ \text { ULU } & 244 & 161(66 \%) & 144(59 \%) & 80 & 2 & 162 & 74 & 2 & 90 & 64 & 2 & 82 \\ \text { UMU } & 187 & 102(55 \%) & 78(42 \%) & 29 & 20 & 138 & 22 & 11 & 72 & 18 & 8 & 56 \\ \text { USM } & 213 & 123(58 \%) & 102(48 \%) & 28 & 29 & 156 & 15 & 16 & 96 & 13 & 16 & 77 \\ \text { USU } & 184 & 121(66 \%) & 96(52 \%) & 23 & 23 & 138 & 24 & 16 & 85 & 24 & 8 & 67 \\ \text { UWM } & 292 & 86(30 \%) & 62(21 \%) & 32 & 45 & 215 & 8 & 19 & 62 & 8 & 5 & 53 \\ \text { SUM } & 1344 & \mathbf{6 7 2 ( 5 0 \% )} & \mathbf{5 4 7 ( 4 1 \% )} & \mathbf{2 1 3} & \mathbf{1 5 0} & \mathbf{9 8 1} & \mathbf{1 4 9} & \mathbf{7 6} & \mathbf{4 7 0} & \mathbf{1 3 3} & \mathbf{4 7} & \mathbf{3 9 1}\end{array}$

550

551 
552 Table 2

553 Table 2. Descriptive data for the predictor variables included in the candidate models. Shown for each variable are the hierarchical level, the

554 mean and median value, the quartiles ( $25 \%$ and $75 \%$ ), and the range of values. Discrepancies in the densities are due to rounding errors when

555 aggregating over the sites. Change in density after translocation refers to the immediate change following translocation in September.

\begin{tabular}{|c|c|c|c|c|c|c|}
\hline Variable & Level & Mean & Median & Q 25\% & Q 75\% & Range \\
\hline Subyearling mass (g) & Individual & 5.2 & 4.5 & 3.7 & 5.8 & $2.7-24.3$ \\
\hline Yearling mass (g) & Individual & 14.0 & 24.6 & 18.1 & 35.5 & $7.4-314$ \\
\hline Total density $\left(\# \cdot 100 \mathrm{~m}^{-2}\right)$ & Site & 13.0 & 11.3 & 6.3 & 19.3 & $1.2-42.2$ \\
\hline Subyearling density $\left(\# \cdot 100 \mathrm{~m}^{-2}\right)$ & Site & 6.5 & 5.5 & 3.4 & 8.7 & $0-26.9$ \\
\hline Yearling density $\left(\# \cdot 100 \mathrm{~m}^{-2}\right)$ & Site & 6.5 & 5.8 & 1.8 & 9.7 & $0-19.4$ \\
\hline Change in total density after translocation (\%) & Site & 74.3 & 0.0 & 0 & 63.8 & $-33.3-1950$ \\
\hline Change in subyearling density after translocation (\%) & Site & 55.2 & 0.0 & 0 & 59.1 & $-43.3-900$ \\
\hline Change in yearling density after translocation (\%) & Site & 84.5 & 0.0 & 0 & 41.2 & $0-3600$ \\
\hline Pool (\%) & Site & 27 & 25 & 17 & 35 & $0-80$ \\
\hline Riffle (\%) & Site & 39 & 39 & 26 & 50 & $0-81$ \\
\hline Run (\%) & Site & 17 & 14 & 0 & 29 & $0-65$ \\
\hline
\end{tabular}


Glide (\%)

Undercut banks (\%)

Overhanging vegetation (\%)

LWD per stream meter $\left(\mathrm{m}^{-1}\right)$

Pool depth $(\mathrm{cm})$

Site depth $(\mathrm{cm})$

Standard deviation of site depth $(\mathrm{cm})$
Site

Site

Site

Site

Site

Site

Site
17

18

52

0.2

5

34

$\begin{array}{llll}11 & 0 & 30 & 0-69 \\ 14 & 4 & 28 & 0-75 \\ 52 & 33 & 72 & 0-100 \\ 0.1 & 0 & 0.2 & 0-1.2 \\ 48 & 42 & 59 & 32-115 \\ 32 & 30 & 38 & 25-53 \\ 15 & 9 & 18 & 7-54\end{array}$


557 Table 3

558 Table 3. Candidate models used to explain the odds of an individual exhibiting site fidelity. All models

559 were specified as having random intercepts at the site level. Information on units and descriptive

560 statistics for the variables are found in Table 2. Corresponding equation refers to the model structures

561 derived in the methods section, and $K$ refers to the number of parameters in the model.

\begin{tabular}{|c|c|c|c|c|c|c|}
\hline $\begin{array}{l}\text { Model } \\
\text { ID }\end{array}$ & $\begin{array}{l}\text { Predictor } \\
\text { variable(s) }\end{array}$ & $\begin{array}{l}\text { Level(s) of } \\
\text { predictor(s) }\end{array}$ & $\begin{array}{l}\text { Corresponding } \\
\text { equation }\end{array}$ & $K$ & $\begin{array}{l}A I C \\
\text { (Subyearlings) }\end{array}$ & $\begin{array}{l}A I C \\
\text { (Yearlings) }\end{array}$ \\
\hline 1 & Mass & Individual & 2 & 3 & 482.36 & 970.76 \\
\hline 2 & Total density & Site & 3 & 3 & 481.85 & 977.44 \\
\hline 3 & Cohort density & Site & 3 & 3 & 480.90 & 977.15 \\
\hline 4 & $\begin{array}{l}\text { Total density + } \\
\text { change }\end{array}$ & Site & 3 & 4 & 483.54 & 978.61 \\
\hline 5 & $\begin{array}{l}\text { Total density + } \\
\text { change }+ \\
\text { interaction }\end{array}$ & Site & 3 & 5 & 484.55 & 980.28 \\
\hline 6 & $\begin{array}{l}\text { Pools + LWD + } \\
\text { undercut + SD site } \\
\text { depth }\end{array}$ & Site & 3 & 6 & 478.86 & 970.86 \\
\hline 7 & Riffle + run & Site & 3 & 4 & 481.50 & 977.12 \\
\hline 8 & $\begin{array}{l}\text { Overhanging veg. + } \\
\text { undercut + LWD }\end{array}$ & Site & 3 & 5 & 482.02 & 976.65 \\
\hline 9 & Glide + site depth & Site & 3 & 4 & 482.98 & 978.14 \\
\hline 10 & Mass + pool & Individual + & 4 & 4 & 482.71 & 968.98 \\
\hline
\end{tabular}




\begin{tabular}{|c|c|c|c|c|c|c|}
\hline & & site & & & & \\
\hline 11 & $\begin{array}{l}\text { Mass + pool + } \\
\text { interaction }\end{array}$ & $\begin{array}{l}\text { Individual + } \\
\text { site }\end{array}$ & 5 & 5 & 484.30 & 970.91 \\
\hline 12 & $\begin{array}{l}\text { Mass + total } \\
\text { density }\end{array}$ & $\begin{array}{l}\text { Individual + } \\
\text { site }\end{array}$ & 4 & 4 & 483.72 & 972.68 \\
\hline 13 & $\begin{array}{l}\text { Mass + total } \\
\text { density + } \\
\text { interaction }\end{array}$ & $\begin{array}{l}\text { Individual + } \\
\text { site }\end{array}$ & 5 & 5 & 483.89 & 974.68 \\
\hline
\end{tabular}

562

563 
564 Table 4

565 Table 4. Average growth rates (\% of body mass per day) by age class, movement, and treatment. The top

566 panel shows growth rates for fish exhibiting site fidelity. The subsequent panels show the growth rates

567 of fish that moved away from their original site, and were recaptured in another site. Standard errors

568 are given in parentheses.

\begin{tabular}{|c|c|c|c|c|}
\hline \multirow[b]{2}{*}{ Movement type } & \multicolumn{2}{|c|}{ Subyearlings } & \multicolumn{2}{|r|}{ Yearlings } \\
\hline & $\mathrm{N}$ & $\begin{array}{l}\text { Avg. growth } \\
\text { rate \% (SE) }\end{array}$ & $\mathrm{N}$ & $\begin{array}{l}\text { Avg. growth } \\
\text { rate \% (SE) }\end{array}$ \\
\hline \multicolumn{5}{|c|}{ Fish exhibiting site fidelity by treatment, no movement } \\
\hline all combined & 88 & $0.84(0.045)$ & 247 & $0.13(0.015)$ \\
\hline original fish in addition sites & 12 & $0.56(0.075)$ & 64 & $0.075(0.022)$ \\
\hline translocated fish from removal sites & 7 & $0.96(0.20)$ & 15 & $0.049(0.049)$ \\
\hline control sites & 69 & $0.87(0.050)$ & 168 & $0.16(0.019)$ \\
\hline
\end{tabular}

Fish in control sites, moving

\begin{tabular}{|c|c|c|c|c|}
\hline all combined & 12 & $0.68(0.091)$ & 38 & $0.20(0.039)$ \\
\hline to another control site & 8 & $0.59(0.11)$ & 25 & $0.23(0.049)$ \\
\hline to removal site & 4 & $0.86(0.10)$ & 8 & $0.15(0.086)$ \\
\hline to addition site & 0 & - & 5 & $0.12(0.068)$ \\
\hline
\end{tabular}

Fish from removal sites, moving away from addition sites

\begin{tabular}{|c|c|c|c|c|}
\hline all combined & 2 & $1.27(0.16)$ & 16 & $0.13(0.071)$ \\
\hline to control site & 2 & $1.27(0.16)$ & 11 & $0.047(0.056)$ \\
\hline back to removal site & 0 & - & 5 & $0.32(0.16)$ \\
\hline
\end{tabular}

Original fish in addition sites, moving 


$\begin{array}{lllll}\text { all combined } & 1 & 0.37(-) & 9 & 0.24(0.098) \\ \text { to control site } & 1 & 0.37(-) & 8 & 0.20(0.10) \\ \text { to removal site } & 0 & - & 1 & 0.58(-) \\ \text { SUM } & 103 & & 310 & \end{array}$

569

570 


\section{Table 5}

572 Table 5. Parameter estimates for the best approximating models for site fidelity in subyearling and 573 yearling steelhead. Shown are the model ID (corresponding to table 3) with the Akaike weights in 574 parentheses, the model parameter estimates, and their associated standard errors (SE).

\begin{tabular}{|c|c|c|c|}
\hline Model ID and weight & Variable & Estimate & $\mathrm{SE}$ \\
\hline \multicolumn{4}{|l|}{ Subyearlings } \\
\hline \multirow[t]{6}{*}{$6(w=0.35)$} & Intercept $\gamma_{00}$ & -1.57 & 0.353 \\
\hline & Pool $\gamma_{01}$ & 1.81 & 0.968 \\
\hline & LWD $\gamma_{02}$ & -1.51 & 0.936 \\
\hline & Undercut $\gamma_{03}$ & 1.85 & 0.936 \\
\hline & SD site depth $Y_{04}$ & -0.0428 & 0.0233 \\
\hline & variance $\tau_{00}$ & 0.0578 & 0.187 \\
\hline \multicolumn{4}{|l|}{ Yearlings } \\
\hline \multirow[t]{4}{*}{$10(w=0.40)$} & Intercept $\gamma_{00}$ & -1.09 & 0.274 \\
\hline & Mass $\gamma_{10}$ & -0.00905 & 0.00371 \\
\hline & Pool $\gamma_{01}$ & 1.47 & 0.742 \\
\hline & variance $\tau_{00}$ & 0.453 & 0.182 \\
\hline \multirow[t]{3}{*}{$1(w=0.16)$} & Intercept $\gamma_{00}$ & -0.693 & 0.180 \\
\hline & Mass $\gamma_{10}$ & -0.00895 & 0.00374 \\
\hline & variance $\sigma_{u}^{2}$ & 0.512 & 0.197 \\
\hline \multirow[t]{3}{*}{$6(w=0.16)$} & Intercept $\gamma_{00}$ & -0.985 & 0.290 \\
\hline & Pool $\gamma_{01}$ & 2.35 & 0.899 \\
\hline & LWD $\gamma_{02}$ & -1.66 & 0.804 \\
\hline
\end{tabular}




$\begin{array}{lrr}\text { Undercut } \gamma_{03} & 1.51 & 0.919 \\ \text { SD site depth } \gamma_{04} & -0.0400 & 0.0185 \\ \text { variance } \tau_{00} & 0.360 & 0.154 \\ \text { Intercept } \gamma_{00} & -1.15 & 0.354 \\ \text { Mass } \gamma_{10} & -0.00713 & 0.00801 \\ \text { Pool } \gamma_{01} & 1.65 & 1.00 \\ \text { Mass } \times \text { pool interaction } \gamma_{11} & -0.00559 & 0.0210 \\ \text { variance } \tau_{00} & 0.450 & 0.182\end{array}$

575

576 


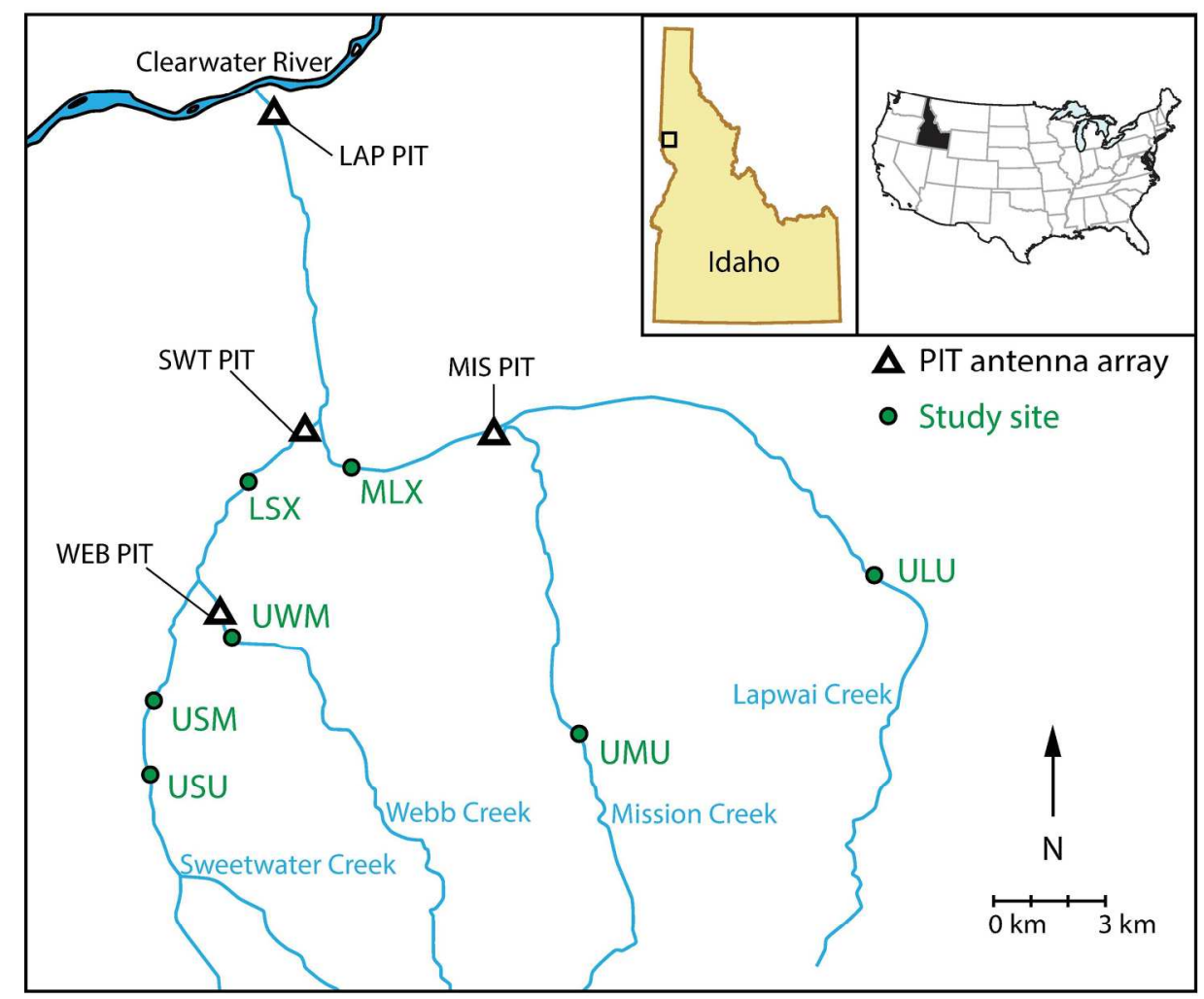

Figure 1. The map shows the location of the study sites in the Lapwai Creek watershed and its location in Idaho, United States (inset). The Clearwater River is a tributary to the Columbia River. (Modified from map data provided by DigitalGlobe, Inc., Colorado, USA) $185 \times 240 \mathrm{~mm}(300 \times 300 \mathrm{DPI})$ 


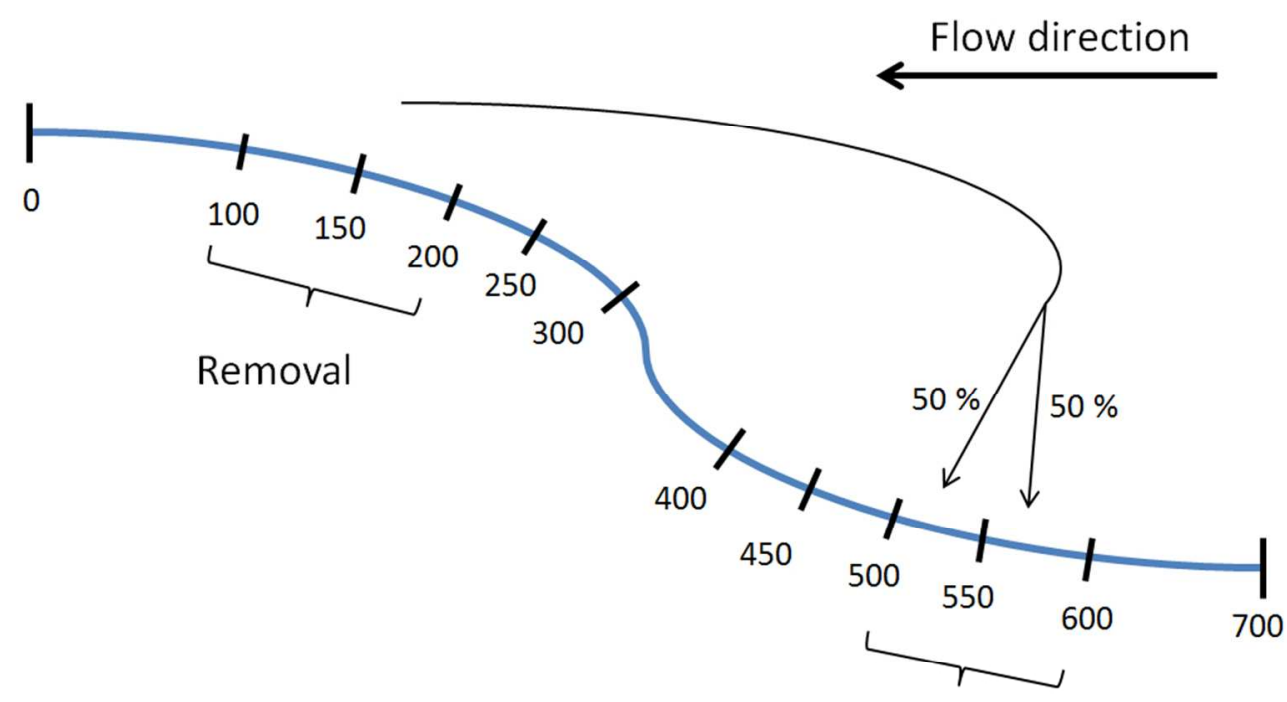

Addition

Figure 2. Experimental design for translocation of juvenile steelhead from two downstream sites (removal) to two upstream sites (addition) in each study reach. Translocated fish were randomized and numbers split evenly among the two upstream sites.

$274 \times 169 \mathrm{~mm}(96 \times 96 \mathrm{DPI})$ 
SEPTEMBER

OCTOBER
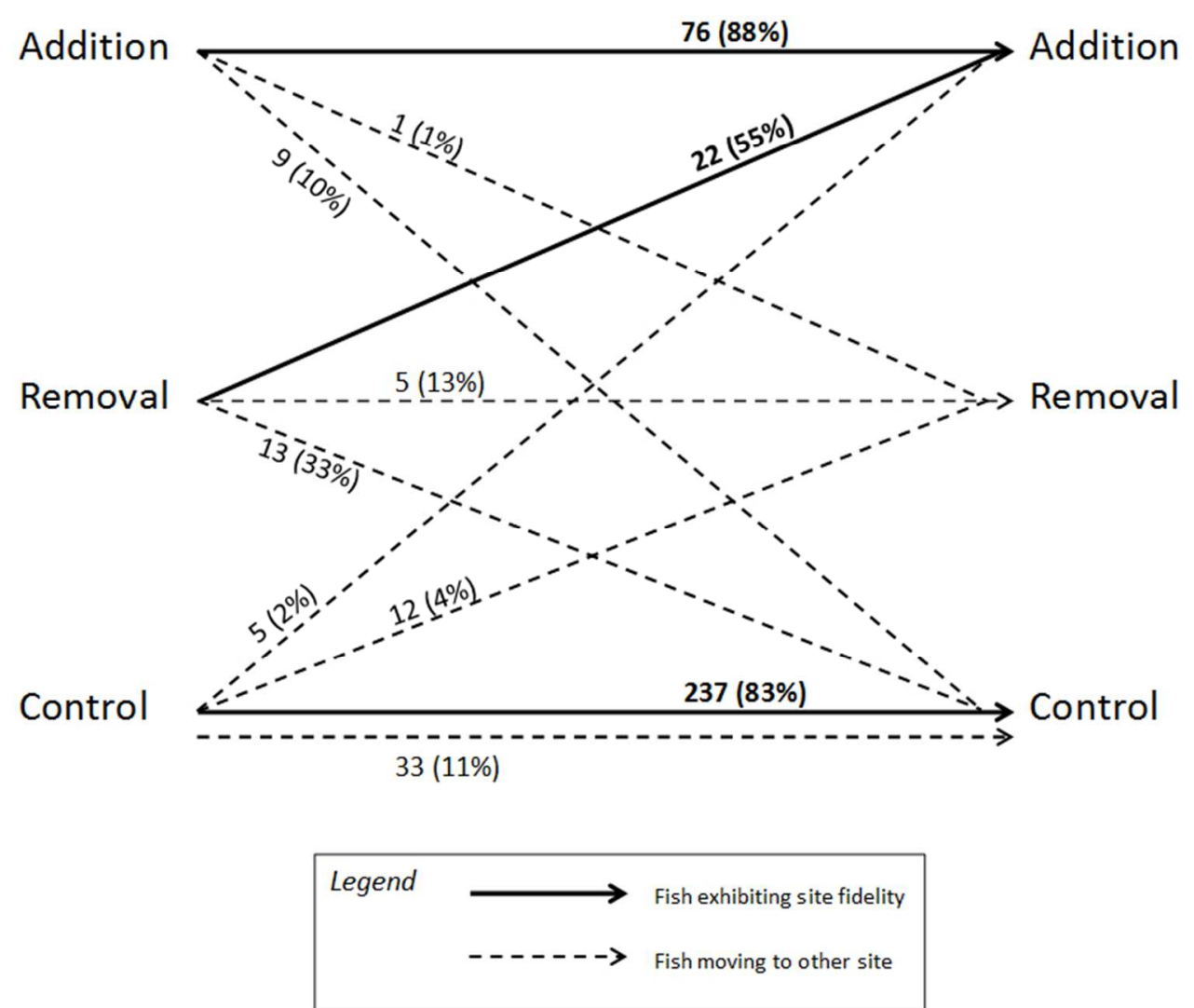

Figure 3. Movement pathways by treatment category over the 28 day experiment, showing the number of fish that remained or moved (percentages in parentheses). Dashed lines refer to fish that moved to a different site, and solid lines denote fish that exhibited site fidelity (for translocated fish, this refers to those that stayed in their new section following translocation). For example, $83 \%$ of fish in control sites exhibited site fidelity during the period whereas $11 \%$ moved to another control site. Note that for translocated fish, five individuals $(13 \%)$ moved back to the site from which they were removed.

$216 \times 205 \mathrm{~mm}(96 \times 96 \mathrm{DPI})$ 
Figure 4

a) Subyearlings

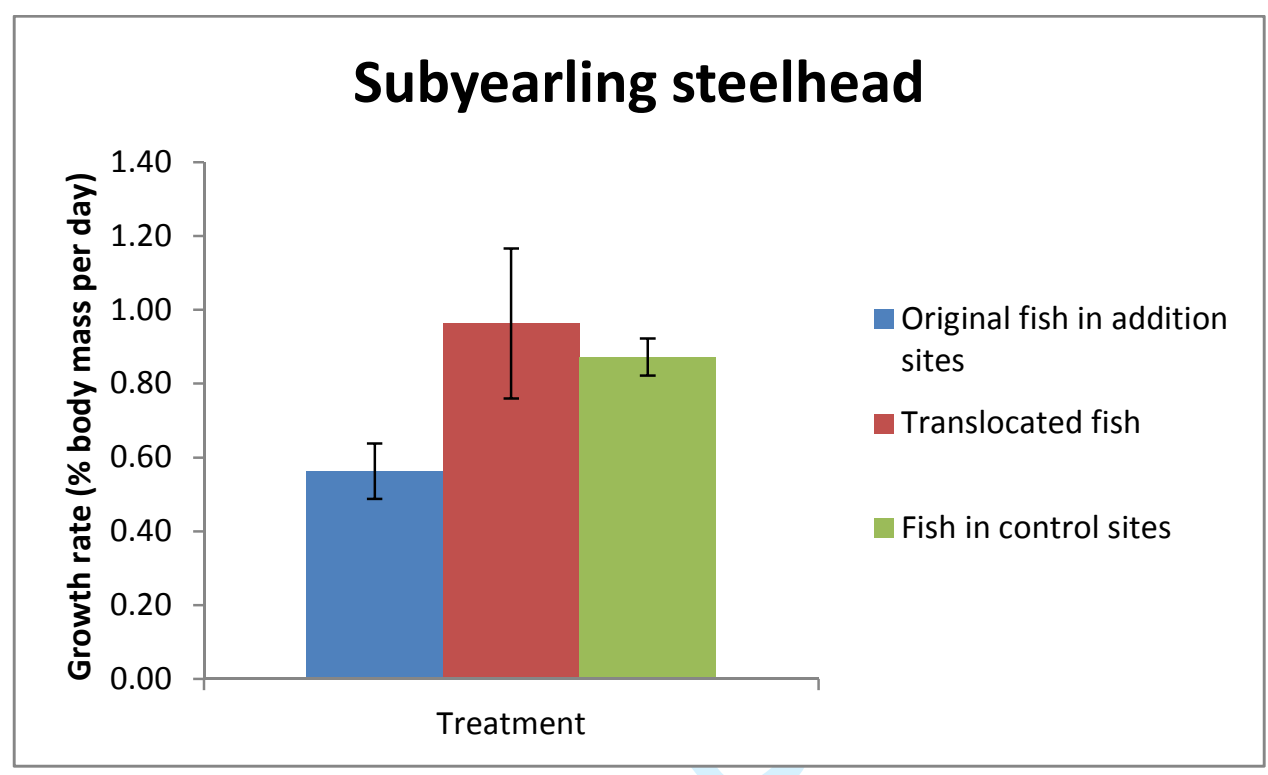

b) Yearlings

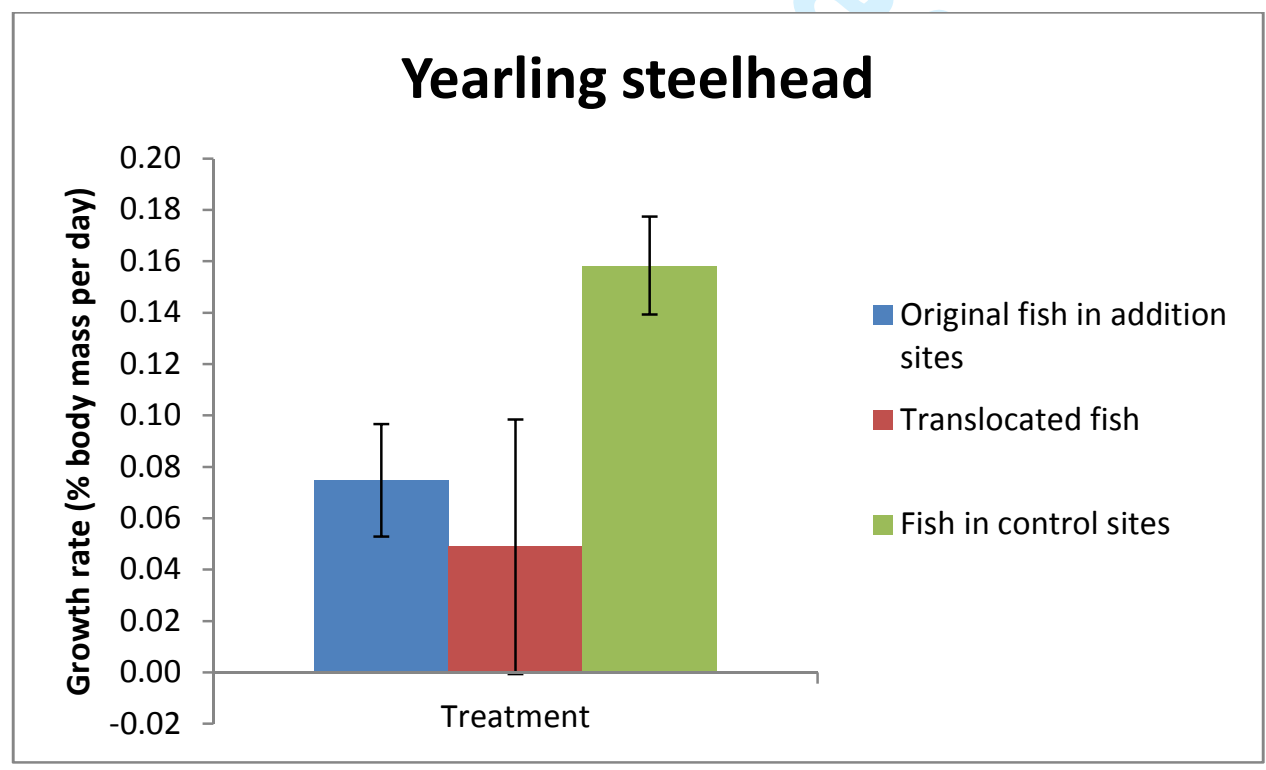


Appendix 1

Raw capture data of juvenile steelhead by treatment category in the Lapwai Creek watershed, 2012. The numbers include both PIT-tagged individuals $>65 \mathrm{~mm}$ fork length, and individuals $<65 \mathrm{~mm}$ which were too small to tag.

\begin{tabular}{lrrrrr}
\hline Treatment & September & October & Total & Change \# & Change \% \\
\hline Control & 1231 & 1140 & 2371 & -91 & -7.4 \\
Addition & 239 & 310 & 549 & 71 & 29.7 \\
Removal & 190 & 218 & 408 & 28 & 14.7 \\
Sum & 1660 & $\mathbf{1 6 6 8}$ & $\mathbf{3 3 2 8}$ & $\mathbf{8}$ & $\mathbf{0 . 5}$ \\
\hline
\end{tabular}


Appendix 2

The study was undertaken before the increased flows in late fall as indicated by the dashed line above the $\mathrm{x}$-axis in the figure below. Discharge $\left(\mathrm{m}^{3} \mathrm{~s}^{-1}\right.$, dashed line) is projected on the right vertical axis, and temperatures $\left({ }^{\circ} \mathrm{C}\right)$ from the warmest and coolest sites of the study are projected on the left vertical axis. We measured the water temperature continuously in each stream segment using HOBO TidbiT v.2 temperature loggers (Onset Computer, Massachusetts, USA). We obtained discharge data from United States Geological Survey stream gauge on Lapwai Creek (USGS gauge \#13342450).

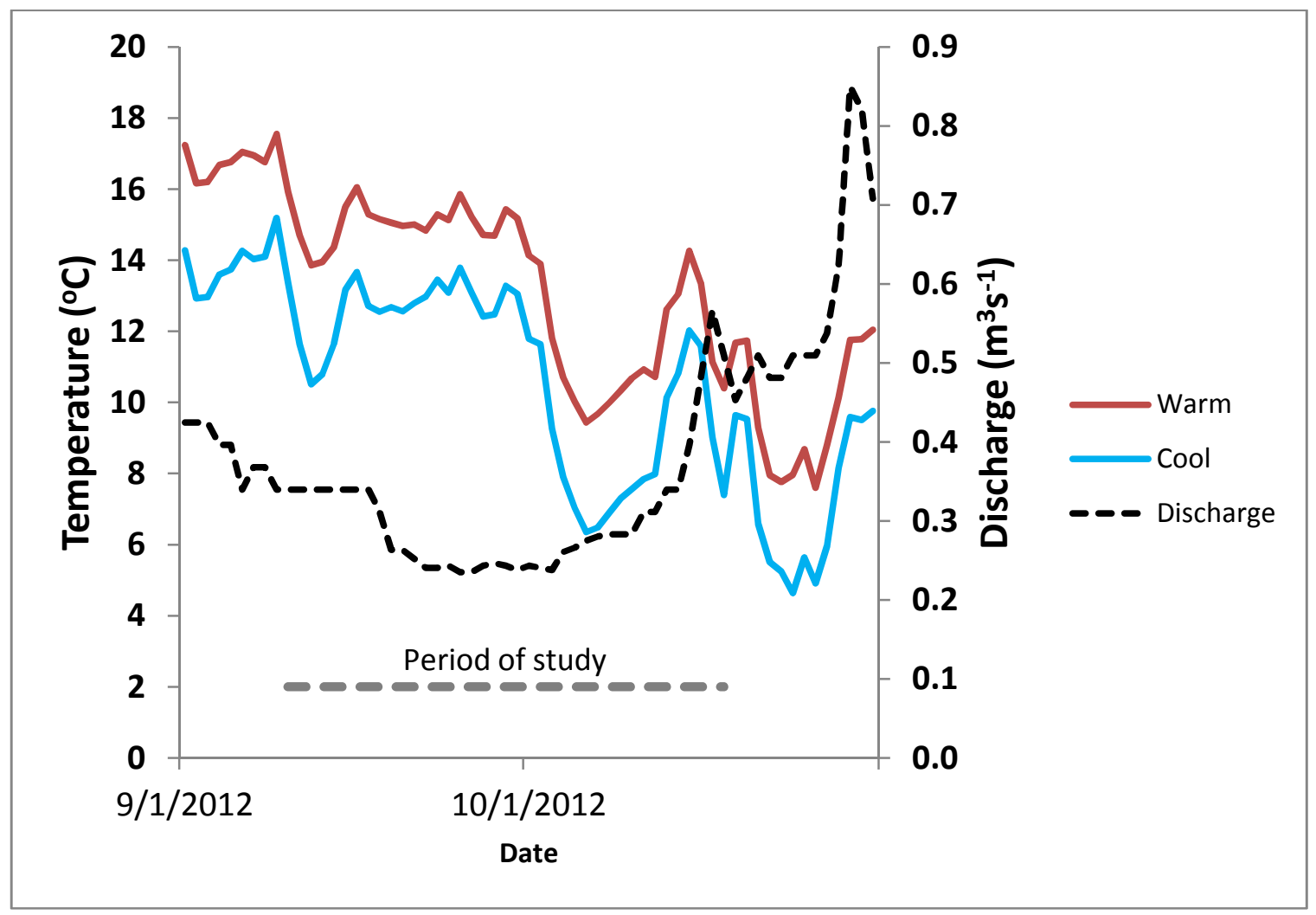




\section{Appendix 3}

Number of PIT-tagged juvenile steelhead detected at PIT tag arrays in the Lapwai Creek watershed over the four-week study. Antenna codes are given following notation by the Columbia River Basin PIT Tag Information System (www.ptagis.org), where LAP is Lapwai Creek, SWT is Sweetwater Creek, MIS is Mission Creek, and WEB is Webb Creek. Arrays are placed at the mouth of each creek, whereby LAP is the lowermost antenna in the Lapwai Creek watershed. Shown for each site is the order of antenna arrays for downstream movement. For example, fish from UMU will encounter two antennae on their downstream movement, MIS and LAP. No tagged individuals left the Lapwai Creek watershed over the course of the study.

\begin{tabular}{lllll}
\hline & & \multicolumn{3}{c}{ Antenna } \\
\cline { 3 - 5 } Stream segment & Antenna order & 1st & 2nd & LAP \\
\hline LSX & SWT-LAP & 5 & n/a & 0 \\
MLX & LAP & n/a & n/a & 0 \\
ULU & LAP & n/a & n/a & 0 \\
UMU & MIS-LAP & 0 & n/a & 0 \\
USM & SWT-LAP & 0 & n/a & 0 \\
USU & SWT-LAP & 0 & n/a & 0 \\
UWM & WEB-SWT-LAP & 69 & 9 & 0 \\
\hline
\end{tabular}


Appendix 4. Correction for capture inefficiency

Because we were unable to recapture all tagged fish on the October visit, the raw capture data underestimated the true abundance. We introduced a simple correction for this by estimating the true abundance (denoted adjusted numbers in Table 1). The consistently high capture efficiencies from previous monitoring of steelhead in the system (2010-2012; Myrvold and Kennedy 2015a) allowed us to develop a linear regression relationship to estimate abundance based on the single-pass electrofishing effort used in this study (Kruse et al. 1998). The average capture efficiency per pass in the monitoring reaches in these segments was 63\% (SD=1.3\%) based on Carle and Strub's (1978) maximum weighted likelihood estimator for three-pass removal data. The linear relationship used to adjust for capture inefficiency for tagged individuals on the October visit in section $i$ was

$$
\text { Adjusted } \text { abundance }_{i}=1.7315+1.5966 \times(\text { captured })_{i},
$$

where captured is the number of steelhead caught during the single-pass electrofishing effort (ordinary least squares; $r^{2}=0.93, F=1308, N=103$, d.f. $\left.=102, p<0.0001\right)$. The statistics for the intercept estimate were $\mathrm{SE}=1.807, t=0.96, p=0.34$, and the statistics for the slope parameter were $\mathrm{SE}=0.0441, t=36.2$, and $p<0.0001$. (We note that more sophisticated methods exist to estimate true abundance [Hartson and Kennedy 2015]; however, for the purpose of this study it was simply a means to better represent the true magnitude of the abundances.)

We also evaluated whether the covariance structure in the data should be modeled explicitly, i.e. whether each segment should have a random intercept. We analyzed the above relationship using a random intercept mixed effects model (Littell et al. 2006) with stream segment as a random effect. The null model likelihood ratio test was nonsignificant (Chi Sq., $p=0.86$ ), which means that modeling the covariance structure of the data was unnecessary (SAS Institute 2008a). The deviation of the random 
effects (i.e. the segment-specific intercepts) from the fixed effects regression line was nonsignificant in all stream segments $(0.85<p|t|<0.98)$, and the fixed-effects parameter estimates were practically identical to the ordinary linear regression estimate reported above (intercept estimate=1.5942, SE=1.93, $t=0.82, d . f .=17.6, p=0.42 ;$ slope estimate $=1.6007, \mathrm{SE}=0.0477, t=33.5, d . f .=52.4, p<0.0001)$.

\section{References}

Carle, F.L., and Strub, M.R. 1978. A new method for estimating population size from removal data. Biometrics 34: 621-630.

Hartson, R.B., and Kennedy, B.P. 2015. Competitive release modifies the impacts of hydrologic alteration for a partially migratory stream predator. Ecol. Freshw. Fish 24: 276-292.

Kruse, C.G., Hubert, W.A., and Rahel, F.J. 1998. Single-pass electrofishing predicts trout abundance in mountain streams with sparse habitat. North Am. J. Fish. Manag. 18: 940-946.

Littell, R.C., Milliken, G.A., Stroup, W.W., and Wolfinger, R.D. 2006. SAS for mixed models. SAS Institute, Cary, NC.

Myrvold, K.M., and Kennedy, B.P. 2015a. Variation in juvenile steelhead density in relation to intream habitat and watershed characteristics. Trans. Am. Fish. Soc. 144: 577-590.

SAS. 2008a. SAS/STAT 9.2 User's guide: The MIXED procedure. SAS Institute, Cary, NC. 